\title{
А.О. Натарова
}

Харківський національний університет Повітряних Сил ім. I. Кожедуба, Харків

\section{ЕЛЕКТРОДИНАМІЧНЕ МОДЕЛЮВАННЯ ЛАЗЕРА НА ОСНОВІ РЕШІТКИ 3І СКІНЧЕННОÏ КІЛЬКОСТІ СРІБНИХ НАНОНИТОК 3 АКТИВНИМИ ОБОЛОНКАМИ}

Розв'язується проблема визначення електромагнітного поля в наявності решітки, щзо складається зі скінченної кількості срібних нанониток, вкритих активними оболонками за відсутності джерела електромагнітного випромінювання. Задля аналізу лазерних мод використовується так звана Лазерна Задача на Власні Значення (ЛЗВЗ). Ми шукаємо частоту лазерної моди, яка має дійсні значення в постановці ЛЗВЗ $i$ відповідне порогове значення посилення в активному матеріалі оболонки. Ми знаходимо ияі двокомпонентні власні значення із характеристичного рівняння, виведеного з використанням розкладання поля кожної нитки в локальних координатах $i$ теорем додавання для ичиліндричних функцій. Це детермінантне рівняння Фредгольма другого роду, яке забезпечує збіжність його коренів. Ми шукаємо траткові лазерні моди $і$ вивчаємо залежності значень порогів самозбудження циих мод і їхніх довжин хвиль від змінних параметрів.

Ключові слова: нанонитка; срібло; решітка; власна мода; траткова мода; поріг; лазерна генерація.

\section{Вступ}

Решітки з субхвильових металевих і діелектричних частинок широко використовуються в сучасній оптиці, фотоніці та оптичних сенсорах. Проведені дослідження [1-3] продемонстрували граткові резонанси з високою добротністю при дифракції світла на решітках зі скінченної кількості срібних і діелектричних нанониток. Такі резонанси можуть досягати майже повного пропускання або відбиття у вузькому частотному діапазоні падаючої плоскої хвилі в обох поляризаціях, мають форму Фано та залежать від кількості розсіювачів. Такі властивості вказують на існування власних мод 3 низькими порогами самозбудження для періодичних структур, виготовлених $з$ активних матеріалів або тих, що включають їх, тобто використовуються як лазери.

Метою даної роботи $\epsilon$ вивчення граткових лазерних мод лазерів на основі решіток зі скінченної кількості срібних нанониток з активними оболонками. Задля цього побудовано електродинамічну модель таких лазерів, що дозволяє знайти частоти та пороги самозбудження їхніх власних лазерних мод.

Нанолазери та лазери на основі нанорозмірних елементів важливі для розвитку сучасних фотоніки, оптоелектроніки і оптичного зондування. Сьогодні вони є об'єктом інтенсивних досліджень [4-7], а першою успішною спробою дослідити граткові моди скінченної решітки з квантових, тобто зроблених 3 активного матеріалу, нанониток була робота [8].

В цій статті використовується математично обгрунтований підхід для електродинамічного моделювання - ЛЗВЗ. Такий підхід вже застосовувався до деяких типів мікро- [9-14] і нано-порожнинних
[15-16] резонаторів. ЛЗВ3 - це електромагнітна гранична задача на власні значення в модифікованому формулюванні, яка адекватним чином враховує наявність активної зони та, як наслідок, дає можливість знайти пороги самозбудження (випромінювання) та зв'язати їх з властивостями дискретного спектру мод у відкритому резонаторі. Вперше іiі було представлено в [9] для двовимірного кругового лазера на мікрорезонаторах, а потім узагальнено для довільних активних порожнин в [17]. У цій постановці активна зона - це частина об'єму резонатора, яка заповнена немагнітним діелектричним матеріалом, що має макроскопічне підсилення. В роботі [8] і тут застосовано такий підхід до моделювання лазерів 3 решіток, що складаються з нанониток. Слід зазначити, що також кілька подібних до ЛЗВЗ формулювань було використано в [18-19].

\section{Виклад основного матеріалу}

\section{Постановка проблеми}

Розглянемо лінійну решітку, представлену на рис. 1 , із $M$ срібних нанониток з радіусами $a_{1}$, кожна 3 яких вкрита однорідною активною оболонкою товщиною $d$ (загальний радіус кожної нитки $\left.a_{2}=a_{1}+d\right)$.

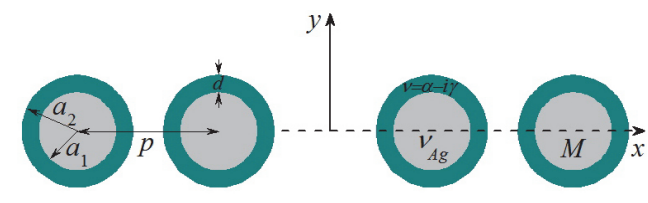

Рис. 1. Лінійна решітка з $M$ срібних нанониток, які вкриті активними оболонками 
Активні оболонки мають комплексний показник заломлення $v=\alpha-i \gamma$, де $\alpha-$ відомий показник заломлення діелектрика, а $\gamma$ - невідомий поріг самозбудження цього активного матеріалу. Період решітки $p$, а центр глобальної системи координат знаходиться посередині решітки. Залежність комплексної діелектричної проникності срібла від довжини хвилі $\varepsilon_{A g}(\lambda)$ взято 3 експериментальної роботи [20] i апроксимовано сплайнами.

В цій роботі розглянуто випадок Н-поляризації (TE). Поле поза нитками і алгоритм отримання коефіцієнтів розкладання поля описані в [2]. Але через наявність другої границі всередині кожної нитки є два додаткових коефіцієнти розкладання поля i, на додачу, $M$ пар граничних рівнянь

$$
\left\{\begin{array}{l}
\sum_{m=-\infty}^{\infty} y_{m}^{(q)} J_{m}\left(v_{A g} k a_{1}\right) e^{i m \varphi_{q}} \\
-\sum_{m=-\infty}^{\infty} v_{m}^{(q)} J_{m}\left(v k a_{1}\right) e^{i m \varphi_{q}}= \\
=\sum_{m=-\infty}^{\infty} w_{m}^{(q)} H_{m}\left(v k a_{1}\right) e^{i m \varphi_{q}}, \\
v_{A g}^{-1} \sum_{m=-\infty}^{\infty} y_{m}^{(q)} J_{m}^{\prime}\left(v_{A g} k a_{1}\right) e^{i m \varphi_{q}}- \\
-v^{-1} \sum_{m=-\infty}^{\infty} v_{m}^{(q)} J_{m}^{\prime}\left(v k a_{1}\right) e^{i m \varphi_{q}}= \\
=v^{-1} \sum_{m=-\infty}^{\infty} w_{m}^{(q)} H_{m}^{\prime}\left(v k a_{1}\right) e^{i m \varphi_{q}},
\end{array}\right.
$$

де $q=1 . . M, k$ - хвильове число у вільному просторі, $J_{m}$ и $H_{m}$ - циліндричні функції Бесселя і Ханкеля 1го роду, відповідно.

$$
\begin{gathered}
\text { Запишемо } w_{m}^{(q)} \text { через } v_{m}^{(q)}: \\
w_{m}^{(q)}=v_{m}^{(q)} S_{m} / P_{m}, \\
S_{m}=J_{m}\left(v k a_{1}\right) J_{m}^{\prime}\left(v_{A g} k a_{1}\right)- \\
-\frac{v_{A g}}{v} J_{m}^{\prime}\left(v k a_{1}\right) J_{m}\left(v_{A g} k a_{1}\right), \\
P_{m}=\frac{v_{A g}}{v} H_{m}^{\prime}\left(v k a_{1}\right) J_{m}\left(v_{A g} k a_{1}\right)- \\
-H_{m}\left(v k a_{1}\right) J_{m}^{\prime}\left(v_{A g} k a_{1}\right) .
\end{gathered}
$$

Далі, згідно [2], масштабуємо невідомі коефіцієнти шляхом підстановки

$$
x_{m}^{(q)}=v_{m}^{(q)} F_{m} J_{m}\left(k a_{2}\right),
$$

i отримуємо матричне рівняння блочного типу (кожен блок нескінченний), яке має наступну форму

$$
X+\tilde{A}\left(k a_{1}, k a_{2}, v_{A g}, \alpha, \gamma\right) X=0,
$$

$$
\begin{gathered}
X=\left\{X^{(q)}\right\}_{q=1}^{M}, X^{(q)}=\left\{x_{m}^{(q)}\right\}_{m=-\infty}^{+\infty}, \\
\tilde{A}=\left\{\tilde{A}^{(q, j)}\right\}_{q, j=1}^{M}, \tilde{A}^{(q, j)}=\left\{\tilde{A}_{m, n}^{(q, j)}\right\}_{m, n=-\infty}^{+\infty}, \\
\tilde{A}_{m, n}^{(j, q)}=\frac{H_{n-m}\left(k d_{j q}\right) V_{m}\left(k a_{1}, k a_{2}, v_{A g}, v\right) J_{n}\left(k a_{2}\right)}{F_{m}\left(k a_{1}, k a_{2}, v_{A g}, v\right) J_{m}\left(k a_{2}\right)} . \\
\cdot e^{i(m-n) \psi_{j q}}, \quad \\
+F_{m}=\frac{S_{m}}{P_{m}} H_{m}\left(v k a_{2}\right) H_{m}^{\prime}\left(k a_{2}\right)+ \\
-\frac{S_{m}}{v P_{m}} H_{m}^{\prime}\left(v k a_{2}\right) H_{m}\left(k a_{2}\right)- \\
-\frac{1}{v} J_{m}^{\prime}\left(v k a_{2}\right) H_{m}\left(k a_{2}\right), \\
V_{m}=\frac{S_{m}}{P_{m}} H_{m}\left(v k a_{2}\right) J_{m}^{\prime}\left(k a_{2}\right)+J_{m}\left(v k a_{2}\right) J_{m}^{\prime}\left(k a_{2}\right)- \\
-\frac{S_{m}}{v P_{m}} H_{m}^{\prime}\left(v k a_{2}\right) J_{m}\left(k a_{2}\right)-\frac{1}{v} J_{m}^{\prime}\left(v k a_{2}\right) J_{m}\left(k a_{2}\right) .
\end{gathered}
$$

Матричне рівняння (6) є рівнянням Фредгольма 2-го роду. Якщо обрізати кожен нескінченний блок (6) на число $N$, то розв'язок такого рівняння прямує до точного зі зростанням $N$. Тому невідомі коефіцієнти розкладання поля можуть бути знайдені із заданою точністю. Перетворення однорідного рівняння (6) у відповідне неоднорідне рівняння таке ж, як у [8].

Перший етап аналізу ЛЗВЗ полягає в пошуку власних пар $(\lambda, \gamma)$, тобто довжин хвиль випромінювання лазерних мод разом з порогами самозбудження. Достатньою умовою існування детермінанту в (6) як функції параметрів задачі $є$ той факт, що це матричне рівняння Фредгольма 2-го роду. Таким чином, потрібно знайти корені детермінантного рівняння

$$
\operatorname{det}\left\{\delta_{m n}+\tilde{A}_{m, n}^{(q, j)}(\lambda, \gamma)\right\}_{\substack{m, n=-\infty \\ q, j=1}}^{\substack{+\infty\\}}=0
$$

Ми розв'язуємо (12), використовуючи метод січних. Для зменшення розміру (6) і (12) можна враховувати симетрію решітки. Також потрібно зазначити, що для алгоритму знаходження $(\lambda, \gamma)$ важлива близькість їхніх початкових наближень до справжніх значень.

\section{Аналіз лазерних мод}

В нашому аналізі ми враховуємо радіус срібної нанонитки $a_{1}$, товщину оболонки $d$, період $p$, кількість ниток в решітці $M$. Дійсна частина показника заломлення $\alpha=1,414$. Досліджувані нанонитки $€$ субхвильовими, у видимому діапазоні їхній радіус не перевищує 100 нм. Досліджені решітки розрі- 
джені, тобто $p>4 a_{2}$. Це дозволяє досліджувати решітки з великим $M$ завдяки використанню менших порядків $N$ усічення блоків матричного рівняння.

Як і у випадку решіток із квантових нанониток [8], в якості початкових наближень довжин хвиль для алгоритму визначення пар власних значень $(\lambda, \gamma)$ ми беремо довжини хвиль граткових резонансів в залежностях повного перерізу розсіяння (ППР) від довжини хвилі при відповідному розсіянні нормально падаючої плоскої хвилі на такій самій решітці, але без накачки $(\gamma=0)$. На рис. 2 представлені нормовані залежності ППР від довжини хвилі для різних решіток зі срібних нанониток з діелектричними оболонками з періодом 450 нм. Як видно 3 цих залежностей, у всіх випадках спостерігається різкий пік граткового резонансу на довжинах хвиль, близьких до значення періоду. Виявлено, що на всіх довжинах хвиль цих граткових резонансів в задачі розсіювання, у ЛЗВ3 існують граткові лазерні моди. Наше дослідження також показало, що основна граткова мода може мати довжину хвилі, величина якої помітно більша, ніж величина періоду решітки (наприклад, $>10$ нм при $p=450$ нм).

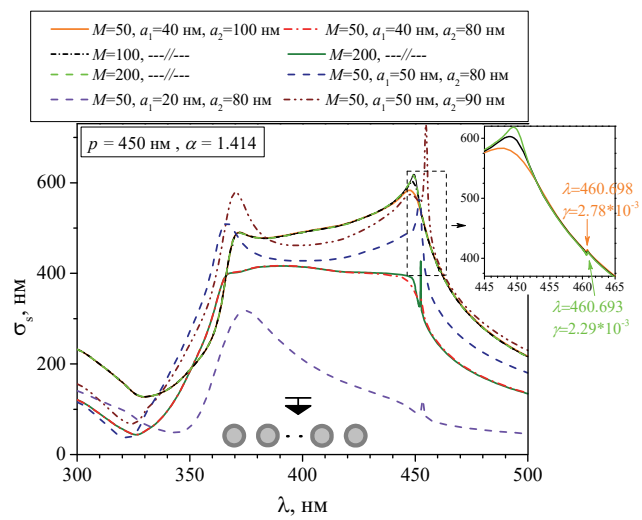

Рис. 2. Нормований ППР як функція довжини хвилі при розсіюванні Н-поляризованої плоскої хвилі

(нормальне падіння) на різних решітках

$(p=450$ нм) зі срібних нанониток

3 діелектричними оболонками $(\alpha=1,414)$ за відсутності накачки $(\gamma=0)$

На графіках ППР у відповідній задачі розсіювання цей випадок ілюструється кривими для решітки $3 a_{1}=40$ нм, $a_{2}=100$ нм, і в цьому випадку резонанс на $\lambda \approx 461$ нм практично непомітний на кривих, але граткова мода знаходиться саме там, хоча в той самий час на $\lambda \approx p$ також спостерігається пік ППР, який збільшується зі збільшенням $M$, але в ЛЗВ3 немає ніяких мод на цій довжині хвилі. Можливо, причина в тому, що навіть при $M=50$ поріг самозбудження цієї моди вже дуже низький $\left(\gamma=2,78 * 10^{-3}\right)$ і в подальшому, зі збільшенням $M$, він зменшується вже дуже повільно.
На рис. 3 представлено траєкторії основних граткових мод решіток зі срібних нанониток з активними оболонками у випадках, коли змінюється один $з$ параметрів решітки: $a_{1}$ або $a_{2}$.
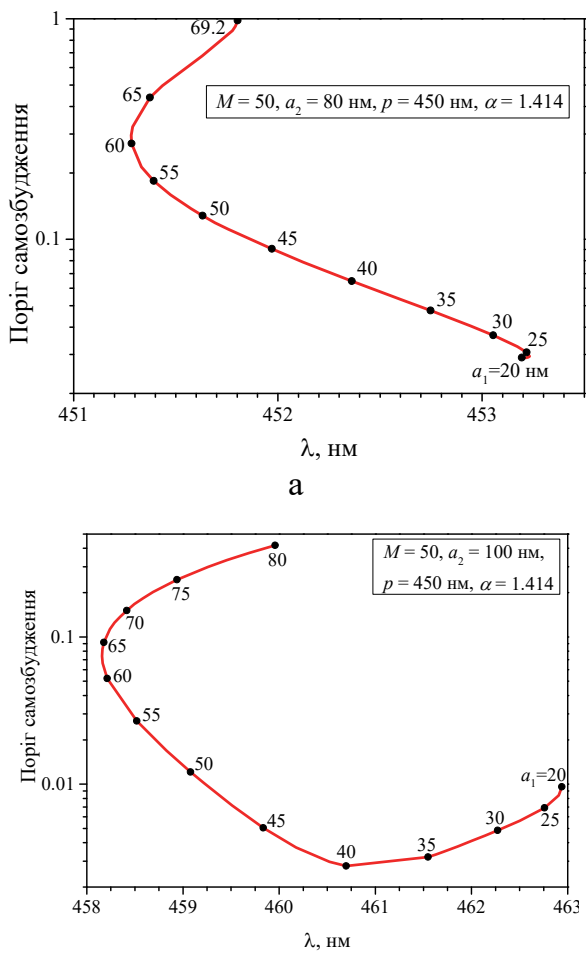

б

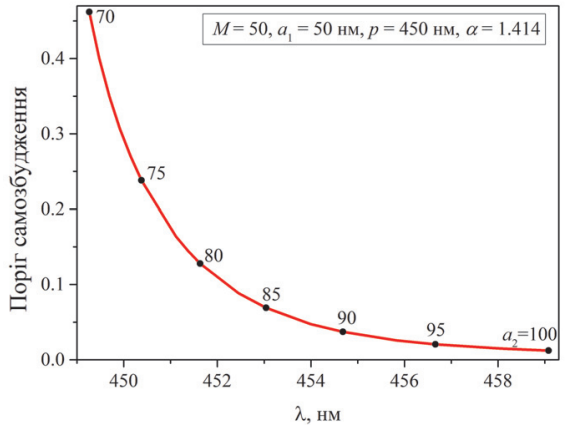

B

Рис. 3. Траєкторії граткових мод на площині $(\lambda, \gamma)$ решіток зі срібних нанониток з активними оболонками при варіюванні одного із параметрів решітки: а, б - радіуси срібної нитки $a_{1} 3$ фіксованим $a_{2}$, в - товщина оболонки 3 фіксованим $a_{1}$

Проаналізувавши ці траєкторії, можна сказати, що всі параметри решітки впливають на довжину хвилі граткової моди і її поріг самозбудження. Видно, що збільшення товщини оболонки з фіксованим радіусом срібної серцевини призводить до гіперболічної форми траєкторії зменшення порогу самозбудження і збільшення довжини хвилі граткової моди. Отже, подальше збільшення товщини оболонки 3 такими радіусами срібної серцевини не призведе до значного зменшення $\gamma$.

На рис. 3, а, 6 показані траєкторії основної граткової моди решітки, коли радіуси $a_{1}$ змінюються (зменшуючись до 20 нм) разом із товщиною оболо- 
нки $d$, а повні радіуси ниток фіксуються на значеннях $a_{2}=80$ нм (рис. 3, а) і 100 нм (рис. 3, б).

Як видно, в першому випадку поріг самозбудження моди зменшується зі зменшенням $a_{1}$, у другому він досягає мінімуму при $a_{1}=40$ нм і далі збільшується, в той час як пороги самозбудження в середньому у десять разів нижчі ніж у першому випадку. Тобто близькість довжини хвилі граткової моди до значення періоду решітки ще не означає, що поріг самозбудження цієї моди низький.

Як було раніше сказано, на рис. 3 представлені траєкторії основної граткової лазерної моди відповідної решітки з нанониток. Для них введемо позначення $G_{11}$. У ближньому полі таких мод “світиться” максимальна кількість ниток решітки (рис. 4, а), тобто поле має яскраві плями поблизу більшості ниток. Але в ході дослідження з'ясувалося, що іс- нують також граткові моди, в ближньому полі яких решітка розділяється на $n=2,3$.. частин (ланцюжків), що “світяться”. Природно, що для великих решіток (з великими $M$ ) існує більше мод $G_{1 n}$. Якщо $n$ парне, то функція поля непарна відносно осі $y$, якщо непарне, то, відповідно, парна. Якщо $M$ мале, то довжини хвиль і пороги самозбудження мод $G_{1 n}$ сильно відрізняються від $G_{11}$, але для великих $M$ через те, що частини цих ланцюжків також містять досить велику кількість ниток, довжини хвиль і пороги мод $G_{12}, G_{13}$ близькі до $G_{11}$. Ближні поля мод $G_{12}$ i $G_{13}$ для решітки 350 нанониток також представлені на рис. 4. Видно, що такі моди мають в кілька разів вищі пороги, ніж основна граткова мода, оскільки ланцюжки, на які ділиться поле цих мод, складаються з невеликої кількості ниток.
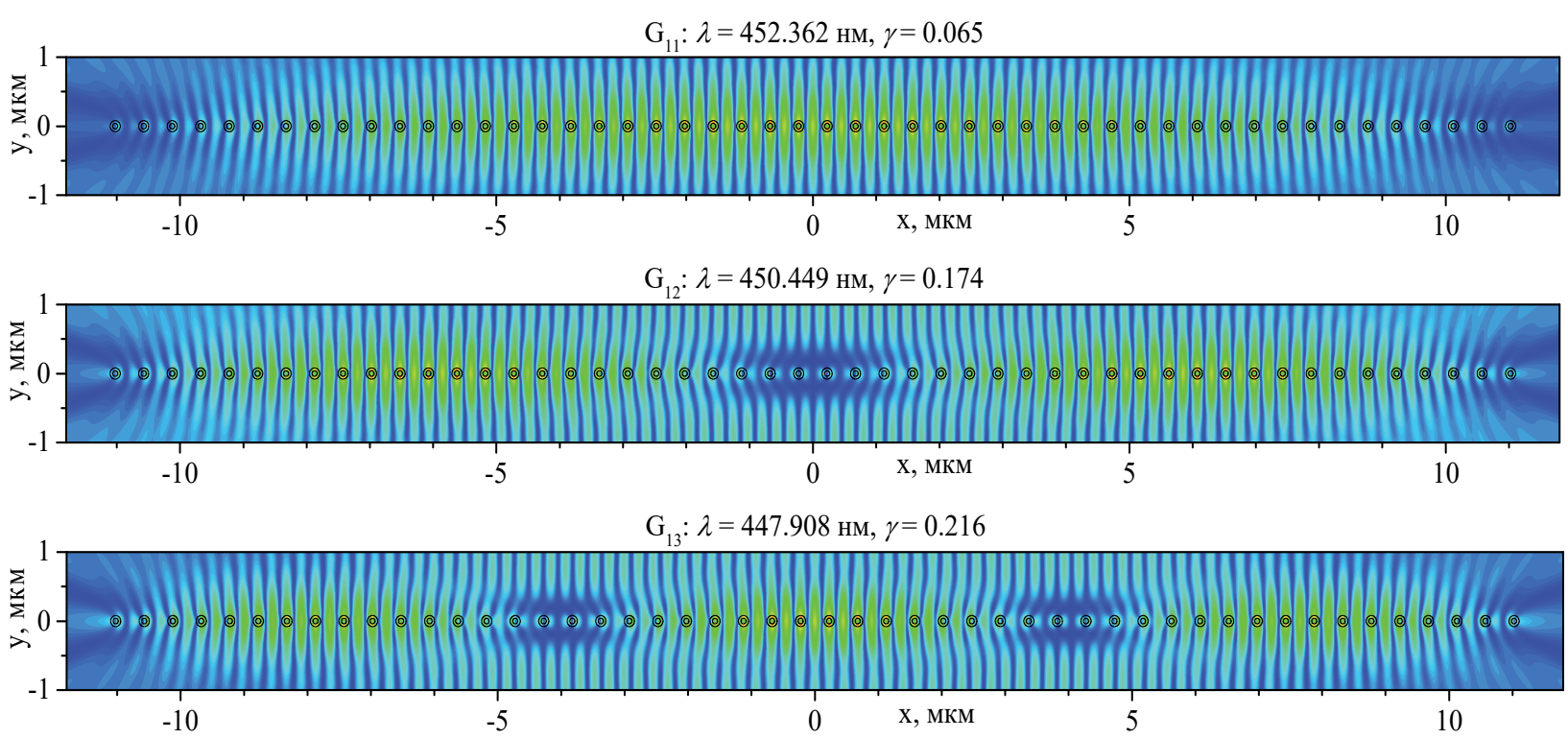

Рис. 4. Картини Н-полів граткових лазерних мод $G_{11}, G_{12}$ та $G_{13}$ для решітки з параметрами $M=50, a_{1}=40 \mathrm{Hм}, a_{2}=80 \mathrm{Hм}, p=450 \mathrm{Hм}$

На рис. 5 представлені траєкторії цих мод разом 3 основною гратковою модою, коли $M$ змінюється від 20 до 1000. Добре видно, що більші решітки мають більш низькі пороги граткових мод. Найбільш різке зменшення порогу самозбудження відбувається при збільшенні кількості ниток до $M=200$.

\section{Висновки}

Представлено електродинамічну модель лазера на основі решітки зі скінченного числа срібних нанониток вкритих активними оболонками. Використовуючи ЛЗВЗ-підхід, представлено спосіб визначення пар власних значень лазерних мод: довжини хвилі випромінювання моди і порога самозбудження активного матеріалу, які можна знайти чисельно 3 контрольованою точністю. В роботі продемонстровано граткові лазерні моди досліджуваних решіток.

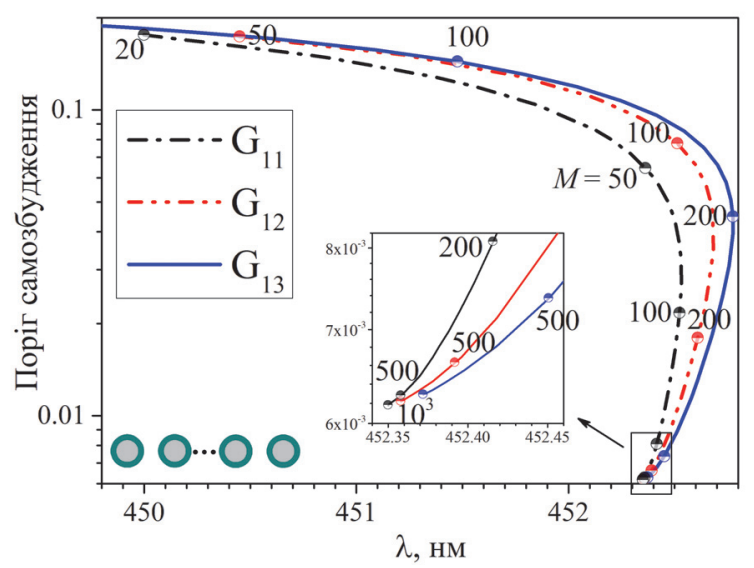

Рис. 5. Траєкторії граткових лазерних мод

$G_{11}, G_{12}$ та $G_{13}$ решітки з параметрами $a_{1}=40$ нм, $a_{2}=80$ нм, $p=450$ нм при різних $M$ 
Їхні пороги самозбудження у багато разів нижчі (близько $\left.10^{-2}-10^{-3}\right)$, ніж у інших типів мод, а хіхні довжини хвиль, як правило, співпадають 3 довжинами хвиль граткових резонансів у відповідній задачі розсіяння плоскої хвилі. У решіток з великого числа нанониток окрім основної граткової моди існують й інші вторинні граткові моди. Зі збільшенням числа нанониток в решітці пороги самозбудження граткових лазерних мод зменшуються, тому що їхня природа зумовлена періодичністю.

\section{Список літератури}

1. Grating resonances on periodic arrays of sub-wavelength wires and strips: from discoveries to photonic device applications" / T.L. Zinenko, V.O. Byelobrov, M. Marciniak, J. Ctyroky, A.I. Nosich // Contemporary Optoelectronics: Materials, Metamaterials and Device Applications. - 2016. -Vol. 199. - P. 65-79. https://doi.org/10.1007/978-94-017-7315-7_4.

2. Effect of periodicity in the resonant scattering of light by finite sparse configurations of many silver nanowires $/$ D.M. Natarov, R. Sauleau, M. Marciniak, A.I. Nosich // Plasmonics. - 2014. - No. 2. - Vol. 9. - P. $389-407$. https://doi.org/10.1007/s11468-013-9636-5.

3. Natarov D. Grating resonances in the scattering of light by periodically structured dielectric nanowires / D. Natarov // Proc. IEEE Int. Conf. MMET-2016. - 2016. - P. 236-238. https://doi.org/10.1109/MMET.2016.7544041.

4. Demonstration of a spaser-based nanolaser / M.A. Noginov, G. Zhu, A.M. Belgrave, R. Bakker, V.M. Shalaev, E.E. Narimanov, S. Stout, E. Herz, T. Suteewong, U. Wiesner // Nature. - 2009. - Vol. 460. - P. 1110-1112. https://doi.org/10.1038/nature08318

5. Deeb C. Plasmon lasers: coherent nanoscopic light sources / C. Deeb, J.-L. Pelouard // Phys.Chem.Chem.Phys. - 2017. Vol. 19. - P. 29731-29741. https://doi.org/10.1039/C7CP06780A.

6. Shahbazyan T.V. Mode volume, energy transfer, and spaser threshold in plasmonic systems with gain / T.V. Shahbazyan // ACS Phot. - 2017. - Vol. 4. - P. 1003-1008. https://doi.org/10.1021/acsphotonics.7b00088.

7. Khurgin J.B. Relative merits of phononics vs. plasmonics: the energy balance approach / Khurgin J.B. // Nanophotonics. 2018. - Vol. 7. - No. 1. - P. 305-316. https://doi.org/10.1515/nanoph-2017-0048.

8. Natarov D.M. Analysis of eigenmodes of laser based on finite quantum nanowire grating / D.M. Natarov // Proc. Int. Workshop DIPED-2018. - 2018. - P. 76-79. https://doi.org/10.1109/diped.2018.8543279.

9. Cold-cavity thresholds of microdisks with uniform and nonuniform gain: quasi-3-D modeling with accurate 2-D analysis / E.I. Smotrova, A.I. Nosich, T.M. Benson, P. Sewell // IEEE J. Sel. Top. Quant. Electron. - 2005. - Vol. 11. - P. $1135-1142$. https://doi.org/10.1109/JSTQE.2005.853848.

10. Lasing frequencies and thresholds of the dipole-type supermodes in an active microdisk concentrically coupled with a passive microring / E.I. Smotrova, T.M. Benson, P. Sewell, J. Ctyroky, A.I. Nosich // J. Opt. Soc. Am. A. - 2008. - Vol. 25. P. 2884-2892. https://doi.org/10.1364/JOSAA.25.002884.

11. Byelobrov V.O. Binary grating of sub-wavelength silver and quantum wires as a photonic-plasmonic lasing platform with nanoscale elements / V.O. Byelobrov, T.M. Benson, A.I. Nosich // IEEE J. Sel. Top. Quant. Electron. - 2012. - Vol. 18, No. 6. - P. 1839-1846. https://doi.org/10.1109/JSTQE.2012.2213586.

12. Smotrova E.I. Optical coupling of an active microdisk to a passive one: effect on the lasing thresholds of the whispering-gallery supermodes / E.I. Smotrova, A.I. Nosich // Opt. Lett. - 2013. - Vol. 38. - No. 12. - P. $2059-2061$. https://doi.org/10.1364/OL.38.002059.

13. Electromagnetic analysis of optimal pumping of a microdisk laser with a ring electrode / A.S. Zolotukhina, A.O. Spiridonov, E.M. Karchevskii, A.I. Nosich // Appl. Phys. B. - 2017. - Vol. 123. - No. 1. - Art. no. 32. https://doi.org/10.1007/s00340-016-6625-3.

14. Spiridonov A.O. Symmetry accounting in the integral-equation analysis of lasing eigenvalue problems for twodimensional optical microcavities / A.O. Spiridonov, E.M. Karchevskii, A.I. Nosich // J. Opt. Soc. Am. B. - 2017. - Vol. 34. No. 7. - P. 1435-1443. https://doi.org/10.1364/JOSAB.34.001435.

15. Natarov D.M. Modes of a core-shell silver wire plasmonic nanolaser beyond the Drude formula / D.M. Natarov // J. Opt. - 2014. - Vol. 16. - No. 6. - P. 075002/6. https://doi.org/10.1088/2040-8978/16/7/075002.

16. Shapoval, O.V. Electromagnetic engineering of a single-mode nanolaser on a metal plasmonic strip placed into a circular quantum wire / O.V. Shapoval, K. Kobayashi, A.I. Nosich // IEEE J. Sel. Top. Quant. Electron. - 2017. - Vol. 23. - No. 6. https://doi.org/10.1109/JSTQE.2017.2718658.

17. Optical theorem helps understand thresholds of lasing in microcavities with active regions / E.I. Smotrova, V.O. Byelobrov, T.M. Benson, J. Ctyroky, R. Sauleau, A.I. Nosich // J. Quant. Electron. - 2011. - Vol. 47. - No. 1. - P. 20-30.

18. Nojima S. Theoretical analysis of feedback mechanisms of two-dimensional finite-sized photonic-crystal lasers $/$ S. Nojima // Appl. Phys. - Vol. 98. - No. 4. - P. 043102/9. https://doi.org/10.1063/1.2001150.

19. Chang S.W. Modeling of micro and nanolaser cavities / S.W. Chang // The Current Trends of Optics and Photonics, Springer Topics in Applied Physics. - 2015. - Vol. 129. - P. 361-376. https://doi.org/10.1007/978-94-017-9392-6_17.

20. Johnson P.B. Optical constants of the noble metals / P.B. Johnson, R.W. Christy // Phys. Rev. B. - 1972. - Vol. 6. P. 4370-4378. https://doi.org/10.1103/PhysRevB.6.4370.

\section{References}

1. Zinenko, T.L., Byelobrov, V.O., Marciniak, M., Ctyroky, J. and Nosich, A.I. (2016), Grating resonances on periodic arrays of sub-wavelength wires and strips: from discoveries to photonic device applications, Contemporary Optoelectronics: Materials, Metamaterials and Device Applications, Vol. 199, pp. 65-79. https://doi.org/10.1007/978-94-017-7315-7_4. 
2. Natarov, D.M., Sauleau, R., Marciniak, M. and Nosich, A.I. (2014), "Effect of periodicity in the resonant scattering of light by finite sparse configurations of many silver nanowires", Plasmonics, No. 2, Vol. 9, pp. 389-407, https://doi.org/10.1007/s11468-013-9636-5

3. Natarov, D. (2016), Grating resonances in the scattering of light by periodically structured dielectric nanowires, Proc. IEEE Int. Conf. MMET-2016, pp. 236-238. https://doi.org/10.1109/MMET.2016.7544041.

4. Noginov, M.A., Zhu, G., Belgrave, A.M., Bakker, R., Shalaev, V.M., Narimanov, E.E., Stout, S., Herz, E., Suteewong, T. and Wiesner, U. (2009), Demonstration of a spaser-based nanolaser, Nature, Vol. 460, pp. 1110-1112. https://doi.org/10.1038/nature08318.

5. Deeb, C. and Pelouard, J.-L. (2017), Plasmon lasers: coherent nanoscopic light sources, Phys.Chem.Chem.Phys., Vol. 19, pp. 29731-29741. https://doi.org/10.1039/C7CP06780A.

6. Shahbazyan, T.V. (2017), Mode volume, energy transfer, and spaser threshold in plasmonic systems with gain, $A C S$ Phot., Vol. 4, pp. 1003-1008. https://doi.org/10.1021/acsphotonics.7b00088.

7. Khurgin, J.B. (2018), Relative merits of phononics vs. plasmonics: the energy balance approach, Nanophotonics, Vol. 7, No. 1, pp. 305-316. https://doi.org/10.1515/nanoph-2017-0048.

8. Natarov, D.M. (2018), Analysis of eigenmodes of laser based on finite quantum nanowire grating, Proc. Int. Workshop DIPED-2018, pp. 76-79. https://doi.org/10.1109/diped.2018.8543279.

9. Smotrova, E.I., Nosich, A.I., Benson, T.M. and Sewell, P. (2005), Cold-cavity thresholds of microdisks with uniform and nonuniform gain: quasi-3-D modeling with accurate 2-D analysis, IEEE J. Sel. Top. Quant. Electron., Vol. 11, pp. 11351142. https://doi.org/10.1109/JSTQE.2005.853848.

10. Smotrova, E.I., Benson, T.M., Sewell, P., Ctyroky, J. and Nosich, A.I. (2008), Lasing frequencies and thresholds of the dipole-type supermodes in an active microdisk concentrically coupled with a passive microring, J. Opt. Soc. Am. A, Vol. 25, pp. 2884-2892. https://doi.org/10.1364/JOSAA.25.002884.

11. Byelobrov, V.O., Benson, T.M. and Nosich, A.I. (2012), Binary grating of sub-wavelength silver and quantum wires as a photonic-plasmonic lasing platform with nanoscale elements, IEEE J. Sel. Top. Quant. Electron., Vol. 18, No. 6, pp. 18391846. https://doi.org/10.1109/JSTQE.2012.2213586.

12. Smotrova, E.I. and Nosich, A.I. (2013), Optical coupling of an active microdisk to a passive one: effect on the lasing thresholds of the whispering-gallery supermodes, Opt. Lett., Vol. 38, No. 12, pp. 2059-2061. https://doi.org/ 10.1364/OL.38.002059.

13. Zolotukhina, A.S., Spiridonov, A.O., Karchevskii, E.M. and Nosich, A.I. (2017), Electromagnetic analysis of optimal pumping of a microdisk laser with a ring electrode, Appl. Phys. B, Vol. 123, No. 1, Art. no. 32. https://doi.org/10.1007/s00340016-6625-3.

14. Spiridonov, A.O., Karchevskii, E.M. and Nosich, A.I. (2017), Symmetry accounting in the integral-equation analysis of lasing eigenvalue problems for two-dimensional optical microcavities, J. Opt. Soc. Am. B, Vol. 34, No. 7, pp. $1435-1443$. https://doi.org/10.1364/JOSAB.34.001435.

15. Natarov, D.M. (2014), Modes of a core-shell silver wire plasmonic nanolaser beyond the Drude formula, J. Opt., Vol. 16, No. 6, pp. 075002/6. https://doi.org/10.1088/2040-8978/16/7/075002.

16. Shapoval, O.V., Kobayashi, K. and Nosich, A.I. (2017), Electromagnetic engineering of a single-mode nanolaser on a metal plasmonic strip placed into a circular quantum wire, IEEE J. Sel. Top. Quant. Electron., Vol. 23, No. 6. https://doi.org/ 10.1109/JSTQE.2017.2718658.

17. Smotrova, E.I., Byelobrov, V.O., Benson, T.M., Ctyroky, J., Sauleau, R. and Nosich, A.I. (2011), Optical theorem helps understand thresholds of lasing in microcavities with active regions, IEEE J. Quant. Electron., Vol. 47, No. 1, pp. 20-30.

18. Nojima, S. (2005), Theoretical analysis of feedback mechanisms of two-dimensional finite-sized photonic-crystal lasers, J. Appl. Phys., Vol. 98, No. 4, pp. 043102/9. https://doi.org/10.1063/1.2001150.

19. Chang, S.W. (2015), Modeling of micro and nanolaser cavities, The Current Trends of Optics and Photonics, Springer Topics in Applied Physics, Vol. 129, pp. 361-376. https://doi.org/10.1007/978-94-017-9392-6_17.

20. Johnson, P.B. and Christy, R.W. (1972), Optical constants of the noble metals, Phys. Rev. B, Vol. 6, pp. 4370-4378. https://doi.org/10.1103/PhysRevB.6.4370.

Надійшла до редколегії 03.02.2020

Схвалена до друку 10.03.2020

\section{Відомості про автора:}

\section{Натарова Анастасія Олегівна}

кандидат фізико-математичних наук

доцент кафедри

Харківського національного університету

Повітряних Сил ім. І. Кожедуба,

Харків, Україна

https://orcid.org/0000-0002-0856-3356

\section{Information about the author:}

\author{
Anastasia Natarova \\ Doctor of Philosophy Ph.D \\ Senior Lecturer \\ of Ivan Kozhedub Kharkiv \\ National Air Force University, \\ Kharkiv, Ukraine \\ https://orcid.org/0000-0002-0856-3356
}




\section{ЭЛЕКТРОДИНАМИЧЕСКОЕ МОДЕЛИРОВАНИЕ ЛАЗЕРА НА ОСНОВЕ РЕШЕТКИ ИЗ КОНЕЧНОГО ЧИСЛА СЕРЕБРЯНЫХ НАНОНИТЕЙ С АКТИВНЫМИ ОБОЛОЧКАМИ}

\section{А.О. Натарова}

Решается проблема определения электромагнитного поля на решетке, которая состоит из конечного числа серебряных нанониток, покрытых активными оболочками в отсутствии источника электромагнитного излучения. Для анализа лазерных мод используется так называемая Лазерная Задача на Собственные Значения (ЛЗСЗ). Мы ищем частоту лазерной моды, которая имеет действительные значения в постановке ЛЗСЗ и соответствующее пороговое значение усиления в активном материале оболочки. Мы находим эти двукомпонентные собственные значения из характеристического уравнения, выведенного с использованием разложения поля каждой нити в локальных координатах и теорем сложения для иүилиндрических функций. Это детерминантное уравнение Фредгольма второго рода, которое обеспечивает сходимость его корней. Мы ищем решеточные лазерные моды и определяем зависимости значений порогов самовозбуждения этих мод и их длин волн от изменяемых параметров.

Ключевые слова: нанонить; серебро; решетка; собственная мода; решеточная мода; порог; лазерная генерация.

\section{ELECTRODYNAMIC MODELING OF LASER BASED ON GRATING OF FINITE NUMBER OF SILVER NANOWIRES WITH ACTIVE SHELLS}

A. Natarova

We solve a source-free problem of the electromagnetic field in the presence of a grating from finite number of silver nanowires coated with active shells. For the electrodynamic modeling we use the mathematically grounded Lasing Eigenvalue Problem (LEP) approach. The LEP is a specific electromagnetic-field eigenvalue problem, which is tailored to extract the wavelengths of the modes together with the associated threshold material gain values from linear Maxwell equations. In our problem statement we look for the frequency of the lasing mode, which has real values in the LEP statement, and for the correspondent value of material gain threshold in the active shell. We find such two-component eigenvalues from characteristic equation, built using the each wire field expansions in local coordinates and addition theorems for cylindrical functions. This is a homogeneous Fredholm second-kind block-type matrix equation. This means that its determinant exists as a function of the parameters of LEP. The Fredholm nature of the matrix operator guarantees that the zeros of the truncated determinant converge to the exact ones if the truncation order gets larger. The roots of such equation we find using the secant method. We find them numerically with controlled accuracy. We look for a lattice lasing modes and study dependences of their threshold values and wavelengths on the variant parameters: silver core radii, number of wires in a grating, shell thickness. We take the initial-guess values of mode's wavelength as the wavelengths of the resonance peaks of the total scattering cross-section spectra in the corresponding scattering problem with the plane wave normal incidence. We demonstrate that the lattice lasing modes have many times lower self-excitation thresholds (about $10^{-2}-10^{-3}$ ) than other types of modes. We also demonstrate that in large gratings, besides the principle lattice mode, there are also other secondary lattice modes. With an increase of the number of nanowires in the grating, the self-excitation threshold of the lattice modes decreases, because of its periodically-caused nature.

Keywords: nanowire; silver; grating; lattice mode; eigenmode; threshold; lasing. 